\title{
Incidência de osteófitos na coluna vertebral*
}

\section{Osteophyte incidence on vertebral column}

\author{
Plínio Marcos Zavanela', Rodrigo Riente', Valdeci Moreira', \\ Marcio Robortella Fernandes ${ }^{2}$, Flávia de Oliveira $^{3}$
}

\begin{abstract}
Zavanela PM, Riente R, Fernandes MR, Oliveira F. Incidência de osteófitos na coluna vertebral. Rev Med (São Paulo). 2008 abr.-jun.;87(2):148-53.

RESUMO: Ao longo do processo de evolução o homem adquiriu a postura ereta. Devido à ação da gravidade surgiram algumas complicações decorrentes dessa postura; entre elas o aparecimento de osteófitos. O objetivo do presente estudo foi verificar a incidência de osteófitos em exames laudados da coluna vertebral e qual a região da coluna mais acometida. Para isso foram utilizados 1089 laudos de 636 indivíduos, sendo 55,5\% mulheres e 44,5\% homens, atendidos em um intervalo de 6 meses, de janeiro a junho de 2006 em uma Clínica de Radiologia particular do Alto Tietê. Os resultados encontrados foram que dos laudos, $26,9 \%$ foram considerados anormais. Das três regiões da coluna vertebral, foram encontrados osteófitos respectivamente para mulheres e homens: $15,4 \%$ e 5,7\% região cervical; $13,6 \%$ e $12,4 \%$ região torácica e $17,9 \%$ e 13,7\% região lombar. O grau de osteófito mais encontrado foi osteófito marginal para as regiões cervical e lombar e labiação marginal predominou na região torácica. Concluiu-se que a incidência de osteófitos do total de laudos analisados foi $26,9 \%$ e a região da coluna mais acometida foi a lombar. Além disso, as mulheres apresentaram mais casos de osteófitos que homens.
\end{abstract}

DESCRITORES: Osteófito/epidemiologia. Coluna vertebral/fisiopatologia. Curvaturas da coluna vertebral/patologia.

* Este trabalho foi realizado na Universidade de Mogi das Cruzes, Mogi das Cruzes, São Paulo. Obteve aprovação do Comitê de Ética em Pesquisa da mesma Instituição e contou com as ilustrações de vértebras de cadáveres cedidas pelo Laboratório de Anatomia da Universidade de São Paulo.

1. Alunos do 8o semestre do curso de Bacharel em Educação Física da Universidade de Mogi das Cruzes.

2. Médico Ortopedista.

3. Doutora em Ciências Morfofuncionais pelo Instituto de Ciências Biomédicas da USP e professora da Disciplina de Anatomia Humana da Universidade de Mogi das Cruzes.

Endereço para correspondência: Flavia de Oliveira. Av. Raimundo Pereira de Magalhães, 1720 - Bloco 20, Apto. 144, Piqueri, São Paulo, SP. CEP. 05145-000. e-mail: fladeo@usp.br 


\section{INTRODUÇÃO}

S: egundo Knoplich"; Oliver e Middleditch ${ }^{11}$, a coluna vertebral possui as funções de permitir o movimento e a deambulação, suportar o homem em sua postura ereta e proteger a medula espinal.

Dangelo e Fattini ${ }^{1}$ afirmam ainda que a coluna vertebral oferece a resistência de um pilar de sustentação na forma de um eixo ósseo, mas também possui a flexibilidade necessária para a movimentação do tronco.

A coluna vertebral é dividida em curvatura primária e secundária sendo a primária a cifose dorsal, por apresentar esta característica desde quando o feto encontra-se no útero numa posição de flexão total, e classifica como secundárias as curvaturas cervical e lombar ${ }^{4}$.

De acordo com Kapandji ${ }^{3}$, as características das curvaturas secundárias se devem à postura ereta adquirida posteriormente. Para Knoplich ${ }^{4}$, tal posição ereta do homem só foi possível com o surgimento das mudanças na coluna, como a lordose lombar e cervical, tendo o homem que equilibrar a cabeça na parte superior da coluna, o tronco em cima dos membros inferiores e o corpo sustentado pela planta dos pés, com isso mudando seu centro de gravidade.

Para adaptar-se à ação da gravidade sobre a coluna vertebral, ocorreram algumas mudanças na coluna, as quais levaram a complicações da mesma. Uma dessas complicações está relacionada à formação óssea anormal, chamada osteófito, conhecido popularmente como "bico de papagaio".

Osteófito é o crescimento excessivo do osso saudável nas vértebras, tendo um papel importante na proteção contra forças compressivas que excedem a capacidade de resistência do osso ${ }^{11}$. Além de proteção, alterações mecânicas e degeneração são fatores comuns do processo de envelhecimento da coluna vertebral tendo como conseqüência os osteófitos ${ }^{9}$.

Malone et al. ${ }^{6}$ relataram que existem dois tipos de osteófitos marginais. Um consiste na proteção para o espaço articular e o outro no desenvolvimento das inserções capsulares das extremidades das articulações. Em ambos os casos, o crescimento do osteófito segue as linhas das forças mecânicas que incidem sobre a área de crescimento dando origem aos osteófitos.

Silva $^{16}$ afirma que uma das causas do surgimento dos osteófitos provêm das forças de compressão em que a coluna vertebral é submetida. Tal compressão poderá afetar raízes nervosas ou até mesmo, em casos mais graves, órgãos e vísceras, como esôfago, traquéia e laringe, podendo causar disfagia, dispnéia, dores e até alterações na voz.

Os osteófitos cervicais são comuns no envelhecimento da população, já a disfagia é incomum, porém como relatado anteriormente, pode ser causada por eles. Maiuri et al. ${ }^{7}$ relatam que os osteófitos hipertróficos cervicais anteriores foram relatados como uma causa da disfagia, com aproximadamente 100 casos descritos na literatura.

Já na região torácica, os osteófitos foram relatados de forma não freqüente, como uma causa de complicações da coluna vertebral tendo a descrição de apenas um caso na literatura em que um osteófito na região torácica anterior obstruiu a haste do brônquio principal direito causando pneumonia obstrutiva crônica 5 .

Oishi et al. ${ }^{10}$, realizaram uma pesquisa com 126 mulheres japonesas com idade média de 60 anos, sendo que todas sofriam de dores na região lombar. Foram realizadas radiografias constando-se que $61 \%$ do total dessas mulheres apresentaram osteófitos naquela região.

Os osteófitos podem refletir a presença de doença comum degenerativa, existindo correlação dos osteófitos com doenças degenerativas em decorrência da escoliose ${ }^{15}$.

Baseado nas conseqüências que os osteófitos podem causar às outras estruturas do corpo, o objetivo do estudo foi verificar a incidência da presença de osteófitos em laudos radiográficos, assim como identificar a região mais comum da coluna (cervical, torácica ou lombar) a apresentar osteófitos, grau de ostéfito e gênero mais acometido.

\section{MATERIAL E MÉTODOS}

Foram utilizados laudos de 1.089 radiografias da coluna vertebral distribuídas entre as três regiões da coluna vertebral: cervical, torácica e lombar nas vistas ântero-posterior e lateral.

Primeiramente foi solicitada a autorização para a utilização dos laudos de radiografias de uma clínica particular do Alto Tietê. Após a autorização da Clínica e aprovação do estudo pelo Comitê de Ética em Pesquisa da Universidade de Mogi das Cruzes, foram realizadas 10 visitas no período de três semanas, sendo estas visitas realizadas no horário estipulado pela Clínica.

Após a autorização, foi feito um levantamento de 1.089 radiografias laudadas da coluna vertebral num período de seis meses, janeiro a junho de 2006. Posteriormente, foram separados os laudos de mulheres $(55,5 \%)$ e homens $(44,5 \%)$, sendo que a faixa etária variou de 5 à 88 anos e 29 à 81 anos, respectivamente. Seguiu-se então a separação dos laudos de acordo 
com a presença ou não de osteófitos, sendo que nos laudos que apresentaram, os mesmos foram ainda separados segundo região da coluna e grau.

De acordo com a nomenclatura utilizada pela clínica, os graus de osteófitos são descritos nos laudos como: Labiação Marginal, em que há uma pequena projeção horizontal do corpo vertebral; Osteófito Marginal, em que há uma extremidade livre encurvada para baixo como um "bico de papagaio"; e Anquilose, em que há fusão óssea entre as vértebras (Figura 1).

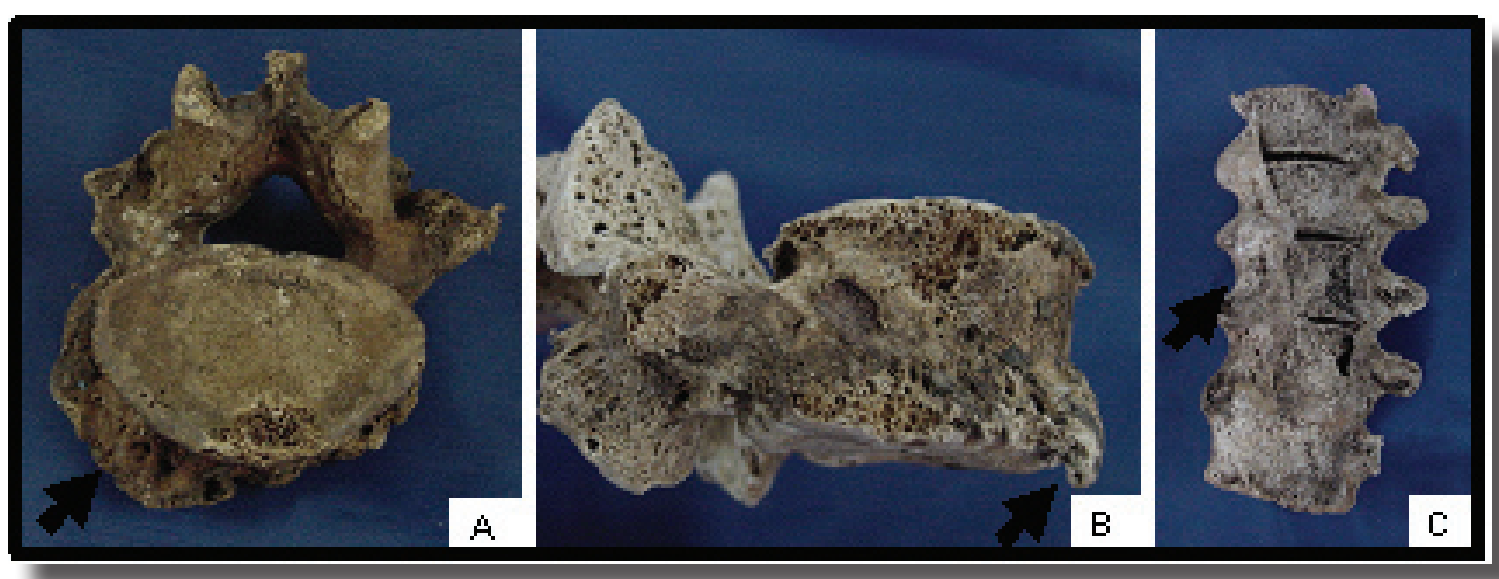

Figura 1. Vértebras maceradas de cadáveres ilustrando em (A) a característica de Labiação Marginal; em (B) Osteófito Maginal e em (C) Anquilose

\section{RESULTADOS}

A análise quantitativa dos dados coletados foi feita por meio da estatística descritiva representada em porcentagem. Os resultados obtidos nesta pesquisa foram apresentados na forma de tabelas, as quais apresentam os dados de freqüência $(F)$ e porcentagem (\%) dos achados.

Tabela 1. Total geral de laudos

\begin{tabular}{l|l|l}
\hline \multirow{2}{*}{ Variável } & \multicolumn{2}{|c}{ Laudos } \\
\cline { 2 - 3 } & $F$ & $\%$ \\
\hline Normal & 795 & 73,1 \\
Anormal & 294 & 26,9 \\
Labiações Marginais & 143 & 13,1 \\
Osteófitos Marginais & 148 & 13,5 \\
Anquilose & 03 & 0,3 \\
\hline Total & 1089 & 100
\end{tabular}

A Tabela 1 representa o total geral de laudos (1.089). Destes, 73,1\% eram normais; o restante, $26,9 \%$, apresentou alguma irregularidade sendo composta de labiações marginais $(13,1 \%)$, osteófitos marginais $(13,5 \%)$ e anquilose $(0,3 \%)$.

Importante observar que do total de laudos anormais os casos de labiações marginais (13,1\%) e de osteófitos marginais (13,5\%) estatisticamente se equivalem, sendo que os casos de anquilose ocorreram somente em três casos.

Tabela 2. Laudos da região cervical de mulheres e homens

\begin{tabular}{c|l|l|l|l|l|l}
\hline \multirow{2}{*}{ Variável } & \multicolumn{2}{|l|}{ Mulheres } & \multicolumn{2}{l|}{ Homens } & \multicolumn{2}{l}{ Total Geral } \\
\cline { 2 - 7 } & $F$ & $\%$ & $F$ & $\%$ & $F$ & $\%$ \\
\hline Exames & 187 & 54,5 & 155 & 45,5 & 342 & 100 \\
Normal & 134 & 39,1 & 136 & 39,8 & 270 & 78,9 \\
Anormal & 53 & 15,4 & 19 & 5,7 & 72 & 21,1 \\
\hline Labiações & & & & & & \\
Marginais & 19 & 5,5 & 12 & 3,7 & 31 & 9,2 \\
\hline Osteófitos & & & & & & \\
Marginais & 34 & 9,9 & 07 & 2,0 & 41 & 11,9 \\
\hline
\end{tabular}

A Tabela 2 representa os exames laudados da região cervical de mulheres e homens, foram no total 342 , sendo $54,5 \%$ mulheres e $45,5 \%$ homens. Os exames normais representaram $39,1 \%$ das muIheres e $39,8 \%$ dos homens, totalizando $78,9 \%$. Já os exames anormais ocorreram em $15,4 \%$ das mulheres 
e $5,7 \%$ dos homens, somando $21,1 \%$. Sendo estes divididos em labiações marginais $(5,5 \%$ mulheres e $3,7 \%$ homens) e osteófitos marginais $(9,9 \%$ mulheres e $2 \%$ em homens). A variável anquilose foi excluída da tabela, pois não ocorreu.

Uma diferença nos resultados chamou à atenção: dos exames anormais, 15,4\% foram de mulheres e 5,7\% de homens. Quanto à classificação dos osteófitos, os que mais ocorreram na região cervical foram os osteófitos marginais $(11,9 \%)$.

Tabela 3. Laudos da região torácica de tulheres e homens

\begin{tabular}{l|l|l|l|l|l|l}
\hline \multirow{2}{*}{ Variável } & \multicolumn{2}{|c|}{ Mulheres } & \multicolumn{2}{c|}{ Homens } & \multicolumn{2}{c}{ Total Geral } \\
\cline { 2 - 7 } & $F$ & $\%$ & $F$ & $\%$ & $F$ & $\%$ \\
\hline Exames & 116 & 47,7 & 127 & 52,3 & 243 & 100 \\
Normal & 83 & 34,1 & 97 & 39,9 & 180 & 74,0 \\
Anormal & 33 & 13,6 & 30 & 12,4 & 63 & 26,0 \\
\hline Labiações & & & & & & \\
Marginais & 23 & 9,5 & 17 & 6,9 & 40 & 16,4 \\
\hline Osteófitos & & & & & & \\
Marginais & 09 & 3,7 & 11 & 4,7 & 20 & 8,4 \\
\hline Anquilose & 01 & 0,4 & 02 & 0,8 & 03 & 1,2 \\
\hline
\end{tabular}

A Tabela 3 representa os exames laudados da região torácica de mulheres e homens. Foram no total 243 , sendo $47,7 \%$ mulheres e $52,3 \%$ homens. Os exames normais representaram $34,1 \%$ das muIheres e $39,9 \%$ dos homens, totalizando $74 \%$. Já os exames anormais ocorreram em $13,6 \%$ das mulheres e $12,4 \%$ dos homens, somando $26 \%$. Sendo estes divididos em labiações marginais $(9,5 \%$ em mulheres e $6,9 \%$ em homens), osteófitos marginais $(3,7 \%$ em mulheres e $4,7 \%$ em homens), e os casos de anquilose ocorreram em $0,4 \%$ e 0,8 das mulheres e homens, respectivamente.

Tanto em mulheres quanto nos homens os casos de labiações marginais prevaleceram em relação aos osteófitos marginais, já para a anquilose ocorreu um caso entre as mulheres e dois nos homens sendo a região torácica a única acometida por este grau.

Também podemos observar ainda que o grau de osteófito que mais ocorreu foi labiação marginal (16,4\%).

A Tabela 4 representa os exames laudados da região lombar de mulheres e homens, os quais apresentaram um total de 504 , sendo $49,4 \%$ mulheres e $50,6 \%$ homens. Os exames normais representaram $31,5 \%$ das mulheres e $36,9 \%$ dos homens, totali- zando $68,4 \%$. Já os exames anormais ocorreram em $17,9 \%$ das mulheres e $13,7 \%$ dos homens somando $31,6 \%$. Sendo esses exames anormais divididos em labiações marginais (8,2\% mulheres e $6,2 \%$ homens) e osteófitos marginais (9,7\% mulheres e 7,5\% homens). A variável anquilose foi excluída da tabela, pois não ocorreu.

Tabela 4. Laudos da região lombar de mulheres e homens

\begin{tabular}{c|l|l|l|l|l|l}
\hline \multirow{2}{*}{ Variável } & \multicolumn{2}{|l|}{ Mulheres } & \multicolumn{2}{l|}{ Homens } & \multicolumn{2}{c}{ Total Geral } \\
\cline { 2 - 7 } & $F$ & $\%$ & $F$ & $\%$ & $F$ & $\%$ \\
\hline Exames & 249 & 49,4 & 255 & 50,6 & 504 & 100 \\
Normal & 159 & 31,5 & 186 & 36,9 & 345 & 68,4 \\
Anormal & 90 & 17,9 & 69 & 13,7 & 159 & 31,6 \\
\hline Labiações & & & & & & \\
Marginais & 41 & 8,2 & 31 & 6,2 & 72 & 14,4 \\
\hline Osteófitos & & & & & & \\
Marginais & 49 & 9,7 & 38 & 7,5 & 87 & 17,2 \\
\hline
\end{tabular}

\section{DISCUSSÃO}

De acordo com a análise do total dos laudos do estudo, foram encontrados indícios de osteófitos (independente do tipo e região da coluna) em 26,9\% dos laudos. Pate et al. ${ }^{14}$ analisaram vértebras de cadáveres separando-as pelo critério de idade, sendo que 200 cadáveres tinham mais de oitenta anos. O resultado foi à freqüência de $95 \%$ de indícios de osteófitos nos 200 cadáveres analisados. Portanto, pode-se encontrar freqüências diferentes de acordo com a faixa etária estudada, uma vez que segundo o referido autor, o aumento da idade é proporcional ao aumento da freqüência de osteófitos.

Os osteófitos estão relacionados com a degeneração óssea, diminuição do espaço interdiscal e progressiva destruição do disco intervertebral, o que explica sua incidência aumentar com o avanço da idade. Figueiredo et al. ${ }^{2}$ analisaram 439 pacientes sintomáticos e não sintomáticos quanto a dores na coluna vertebral e chegaram à conclusão de que a presença de osteófitos se dava em $68,6 \%$ dos a pacientes com idade acima de 40 anos, o que reafirma que o aumento da faixa etária é diretamente proporcional aos achados de osteófitos na coluna vertebral. O'Neill et al. ${ }^{12}$ analisaram 681 mulheres e 499 homens com média de idade em torno de 64 anos e encontraram 
acometimento de osteófitos em $84 \%$ dos homens e $74 \%$ das mulheres.

Além da faixa etária estudada, verificou-se também uma diversidade na literatura para determinar o tipo de osteófito, sendo utilizado o termo grau ou ainda uma descrição da aparência do osteófito. Nathan ${ }^{8}$, após estudar 400 colunas vertebrais definiu os seguintes graus: I, tendo o osteófito apenas um início de hiperostose; II, consistindo de uma protusão óssea que se projeta horizontalmente do corpo vertebral; III, com a forma característica de "bico de papagaio" se projetando para a vértebra inferior e IV, em que os osteófitos de duas vértebras vizinhas se projetam até se unirem. Já O’Neill et al. ${ }^{12}$ utilizaram um "score" para classificar os osteófitos, sendo $0=$ nenhum; 1 = duvidoso; 2 = leve; 3 = moderado e 4 = severo. Watanabe e Terazawa ${ }^{17}$ também utilizarem um escore para a classificação dos osteófitos, porém variando de zero a três.

Outra forma de descrição se refere à presença de labiação marginal ou de osteófito marginal, sendo que o primeiro refere-se ao grau I e o segundo aos graus II e III e o último grau (IV) equivalente à anquilose. Em exames laudados, percebe-se a preferência pelo segundo tipo de descrição, uma vez que a diferença entre graus se torna muito sutil para a observação através de um exame de Raio X, em que muitas vezes possui sobreposição de imagens, dificultando a distinção de pequenos detalhes quanto ao grau do osteófito.

A quantidade de laudos analisados neste estudo para homens e mulheres foi praticamente a mesma para cada região da coluna investigada (Tabelas 2, 3 e 4), porém, quando se compara a freqüência de anormalidades nas regiões cervical e lombar, foi encontrado que as mulheres possuem maior freqüência de osteófitos os homens. Portanto, de acordo com a população analisada nesse estudo, as mulheres foram mais acometidas pela presença de osteófitos. Pesquisa realizada por Paiva et al. ${ }^{13}$, revelaram através de radiografias de 96 mulheres na pós-menopausa com osteoporose diagnosticada, que $16,7 \%$ delas apresentaram osteófitos na região lombar, dado semelhante ao do presente estudo, cuja freqüência encontrada nessa curvatura para mulhe- res foi de $17,9 \%$. Ainda que no presente estudo não tenha sido investigado a relação de pós-menopausa e osteoporose em mulheres, essa pode ser uma justificativa do maior aparecimento de osteófitos em mulheres se comparadas aos homens.

De todos os 1.089 laudos analisados, apenas três apresentaram anquilose. Tal tipo de ossificação entre as vértebras pode ocorrer devido à calcificação do ligamento longitudinal anterior ${ }^{14}$. A Figura 1C, a qual apresenta um segmento de vértebras maceradas e anquilosadas, parece confirmar tal afirmação, uma vez que o segmento de ossificação coincide com a localização anatômica do ligamento longitudinal anterior, o qual se estende por toda a região anterior da coluna vertebral.

No estudo comprovou-se que a região lombar apresentou mais exames anormais $(31,6 \%)$ em relação às regiões cervical e torácica. Figueiredo², em um estudo radiológico da coluna lombar sintomática e assintomática, refere que realmente a procura do ortopedista para problemas relacionados à coluna vertebral é muito mais freqüente para a região lombar do que para as demais regiões. É possível que isso explique o fato de se ter mais osteófitos nessa região mais acometida por dor.

\section{CONCLUSÃO}

Foi possível concluir que nos laudos analisados houve a presença de osteófitos nas três regiões da coluna vertebral, porém a região lombar foi a mais acometida. O grau de osteófito mais comum nas regiões cervical e lombar foi o osteófito marginal. Já na região torácica, o grau que mais ocorreu foi a labiação marginal. Apesar dessas diferenças, no total geral de laudos, labiações e osteófitos marginais se equivaleram.

Conclui-se também que nas mulheres ocorreram mais casos de osteófitos em relação aos homens. Seria interessante, em novos estudos, relacionar os exames de imagem não somente ao sexo e faixa etária, mas também aos hábitos de vida diária e ainda ao fato de serem ou não sintomáticos.

Agradecimento - Ao Laboratório de Anatomia da Universidade de São Paulo por ceder as imagens das vértebras de cadáveres maceradas apresentadas na Figura 1. 
Zavanela PM, Riente R, Fernandes MR, Oliveira F. Osteophyte incidence on vertebral column. Rev Med (São Paulo). 2008 abr.-jun.;87(2):148-53.

\begin{abstract}
With the evolution of mankind appeared the erect posture. Due to gravity action complications appeared because of this posture, like the osteophytes. The aim of this study was to investigate osteophyte incidence on vertebral column and the most affected column region. For this were used 1089 reports of 636 patients: $55.5 \%$ women and $44.5 \%$ men, attended between january and june of 2006 in a privet Clinic on Alto do Tietê, region of São Paulo. Results revealed that $26.9 \%$ of reports had alterations. Region's analysis revealed osteophytes in men and women, respectively: $15.4 \%$ and $5.7 \%$ on cervical region; $13.6 \%$ and $12.4 \%$ on thoracic region and $17.9 \%$ and $13.7 \%$ on lumbar region. The most common kind of osteophyte was marginal osteophyte on cervical and lumbar regions and marginal labium was predominant on thoracic region. The incidence of osteophytes on vertebral column was $26.9 \%$ and lumbar region was the most affected. Besides, women have more osteophytes cases than men.
\end{abstract}

KEY WORDS: Osteophyte/epidemiology. Spine/physiopathology. Spinal curvatures/pathology.

\title{
REFERÊNCIAS
}

1. Dangelo JG, Fattini CA. Anatomia humana sistêmica e segmentar. São Paulo: Atheneu; 1995.

2. Figueiredo JDS, Bacelar JJF, Figueiredo TA. Estudo radiológico comparativo da coluna lombar sintomática e assintomática. Rev Bras Ortop. 1984;19(4):150-6.

3. Kapandji I. A. Fisiologia articular. São Paulo: Manole; 1990.

4. Knoplich J. Enfermidades da coluna vertebral. São Paulo: Panamed Editorial; 1986.

5. Leon JA, Calamia KT, Leventhal JP. Cronic obstructive pneumonia caused by a vertebral body osteophyte. Mayo Clin Proc. 2000;75(2):185-8.

6. Malone T, McPoil T, Nitz AJ. Fisioterapia em ortopedia e medicina no esporte. São Paulo: Ed. Santos; 2000.

7. Maiuri F, Stella L, Sardo L, Buonamassa S. Dysphagia and diypnea due to na anterior cervical osteophyte. Arch Orthop Trauma Surg. 2002;122(4):245-7.

8. Nathan H. Osteophytes of the vertebral column - an anatomical study of their development accordind to age, race, and sex with considerations as to their etiology significance. J Bone Joint Surg (Am). 1962;(44):243.

9. Nathan M, Pope MH, Grobler LJ. Osteophyte formation in the vertebral column: a review of the etiologic factors - part II. contemporary orthopedy. 1994;29(2):113-9.

10. Oishi $Y$, Shimizu K, Katoh T, Nakao H, Yamamura M, Furuko T, et al. Lack of association between lumbar disc degeneration and osteophyte formation in elderly japanese women with back pain. Bone. 2003;32(4):405-11.

11. Oliver J, Middledith A. Anatomia funcional da coluna vertebral. Rio de Janeiro: Revinter; 1998.

12. O'Neil TW, McCloskey EV, Kanis JA, Bhalla AK, Reeve J, Reid DM, et al. The distribuition, determinants, and clinical correlates of vertebral osteophytosis: a population based survey. Rheumatology. 1999;26(4):842-8.

13. Paiva LC, Filardi S, Pinto AM. Impact of radiographic abnormalities and vertebral fractures on spinal bone density of women with osteoporosis. Sao Paulo Med J. 2002;120(1):9-12.

14. Pate D, Goobar J, Resnick D, Haghighi P, Sartoris DJ, Pathria MN. Traction osteophytes of the lumbar spine: radiographic-pathologic correlation. Radiology. 1988;166:843-6.

15. Richter DE, Nash CLJ, Moskowits RW, Goldberg VM., Rosner IA. Idiopathic adolescent scoliosis - a prototype of degenerative joint disease. The relation of biomechanic factors to osteophyte formation. Clin Orthop Related Res. 1985;(193):221-9.

16. Silva MAG. Coluna vertebral. São Paulo: Panamed Editorial; 1985.

17. Watanabe S, Terazawa, K. Age estimation from the degree of osteophyte formation of vertebral columns in Japanese. Leg Med (Tokyo). 2006;8(3):156-60. 